\title{
Tensile and Bending Analysis of Fabric Reinforced Graded Epoxy Composites
}

\begin{abstract}
MARA DIMOFTE, MARINA BUNEA, ANA CAPATINA, ADRIAN COJ AN, RADU BOSOANCA, ADRIAN CIRCIUMARU*
Dunarea de Jos University, 47 Domneasc Str. 800008, Galati, Romania

Due their various applications the fabric reinforced polymer composites are subject of a large number of researches especially for aero- and automotive industry. Regarding the last domain there are huge interests in designing and forming composites with controllable strengthens for car bodies able to protect both the driver and passengers inside and pedestrians in case of unfortunate events. In this regard, based on previous studies developed at the Research and Development Centre for Thermoset Matrix Composites, our proposal is to design the bending behaviour of a fabric reinforced materials by means of changing the bending strength of the polymer matrix using a solvent. 1-Methyl, 2- pyrrolidinone is a well-known polymer solvent that had been used in previous studies as vector to transfer various organic agents into epoxy resins. During those studies it had been noticed that the presence of above mentioned solvent is changing the bending behaviour of polymer samples and induces some properties that are belonging to memory-shape materials. The presentstudy is related to mechanical analysis of a multi-layered material (fabric layers) immersed into an epoxy resin having a graded bending strength.
\end{abstract}

Keywords: modified epoxy resin, fabrics, bending behaviour, tensile modulus

The current industrial orientation toward sustainable development and environment protection leads to an increase in using of alternative sources of energy especially for automotive industry starting with motorization and ending with car bodies. If the motorization is no longer a problem the car bodies are still representing a challenge because they have to fit two general classes of requirements: on one hand the auto vehicles have to be light enough to ensure a suitable ratio between the engine power and the car weight and, on the other hand requirements regarding safety of driver, passengers and pedestrians. Of course, in the case of electric auto vehicles, there are some issues regarding the autonomy i.e. issues regarding batteries recharging but it seems that is solvable by using photovoltaic elements integrated into car bodies.

During the last two decades the use of composites was spreading over almostall the industrial applications starting with aero-spatial and ending with sports especially due the fact that their properties are designable from the matrix and immersed elements properties and ending with forming technique. Of course composite elements involves some disadvantages such as difficult (or impossible) reparation and hard neutralization after the life period (waste managementfor environment protection) but these disadvantages are compensated by major advantages as reduced specific weight, higher strengthens and, of course the fact that a composite part do not need special technologic interventions after formation.

The presentstudy was determined by a research project presented at the Sicomp Conference 2015, Composites in Automotive Applications, regarding composites with controllable strength for car bodies applications.

Since the main activity of Research and Development Centre for Thermoset Matrix Composites of Dunãrea de Jos University is to design, to form and to test composites, during last decade many research subjects had been purposed especially as doctoral studies and a few as research projects this is why the idea of designing a material with controllable strength was challenging enough to start a research based on the experience of fabric reinforced composites and diluted epoxy resins. The main principle is to form a material with epoxy matrix and fibre fabric reinforcement but providing the matrix with a gradient of strength.

The functional graded composites are not a new subject since they were studied for past decades but generally these materials are regarded as graded at structural level and are seen as applicable for various purposes with a large class of loadings - mechanical, thermal, thermomechanical, electromagnetic based on their particular response. In this regard it is about gradation, both on surface layers or on volume and an excellent review of obtaining techniques and properties of such materials is presented in [1]. Many researchers had developed various models to study the properties of functionally graded materials especially for polymer matrix materials [2-14]. Of course many of these studies are punctual but some of them are containing useful information in understanding the way these materials are responding to various loadings in various conditions.

As a general tendency regarding fibre reinforced composites the use of carbon fibre might be noticed especially because they are electrical conductors together with their excellent mechanical properties. In this direction the carbon fibre could be used to offer suitable information regarding the state of the material [15-23].

The use of fabrics together with the possibility of changing the basic properties of epoxy systems lead to an opportunity to design the properties of a polymer matrix composite by both alternating various types of fabrics and modifying the properties of matrix at different levels on the depth of the composite plate. Based on previous studies regarding mechanical response of fabric reinforced composites [24-27] and properties of modified epoxy systems [28-31] the actual study is oriented toward analysis 
of mechanical properties of fabric reinforced plates with graded polymer matrix.

\section{Experimental part}

Materials and method

The analysed materials were obtained by wet lay-up technique with each layer of reinforcement being imbued with pre-polymer mixture of the epoxy system and being placed into a glass mould. Each plate of material, having approximate dimensions of $280 \times 210 \times 4 \mathrm{~mm}$, consists of 15 layers of reinforcement made of five different types of fabrics as it may be seen in table 1 - the orientation angle is measured from the longest edge of the plate (mould). All the fabrics are of simple type (simple alternation of weft and warp tows of untwisted fibres) but the last three layers that are made of special fabric obtained by a special technique of spreading a $1 \mathrm{k}$ tow of carbon fibres (TEXtrem) as it can be seen in table 2 and figure 1 .

Priory to formation, adhesion test were performed and the results were enough good to decide to form the plates without a special treatment applied to the fabrics (even this decision was wrong as it will be seen). Each fabric was cut in pieces to fit the mould dimensions and each

piece of fabric was imbued with the pre-polymer mixture before being placed into the mould. As matrix for materials four epoxy systems were used, namely: Epiphen RE 4020/ DE4020 (Resoltech), Epoxy resin HT 2, Epoxy resin C and Epoxy resin $L$ (all the last three from $R \& G$ Faserverbundwerkstoffe $\mathrm{GmbH}$ ). For all these resins the right amount of 1-Methyl, 2-pyrrolidinone was mixed for 15 min into the main component of epoxy system (the resin) and after that the other component ( hardener) was added and the stirring was continued for another ten minutes.

Due to the way of formation the concentration of 1Methyl, 2-pyrrolidinone is graded, there is an approximate linear variations from 0 to $20 \%$ from the first moulded reinforcement layer to the last moulded reinforcement layer. The presence of 1-Methyl, 2-pyrrolidinone is introducing some special properties of epoxy resin such as memory shape and it is modifying the mechanical response of the material from the bending and tensile point of view (i.e. the bending modulus and the tensile modulus have modified values from the ones corresponding to the epoxy systems). After formation all the plates were thermally cured to reach the best mechanical performances of polymers (according to polymers producers' recommendations).

\begin{tabular}{|c|c|c|c|}
\hline Layer & Fabric & Orientation & Matrix \\
\hline 01 to 03 & C240 & $0^{\circ}$ & Epoxy resin \\
\hline 04 to 06 & C/A68 & $45^{\circ}$ & Epoxy resin with 5\%(wr) 1-Methy1, 2- pyrrolidinone \\
\hline 07 to 09 & C160 & $0^{\circ}$ & Epoxy resin with 10\% (wr) 1-Methy1, 2- pyrrolidinone \\
\hline 10 to 12 & A61 & $45^{\circ}$ & Epoxy resin with 15\% (wr) 1-Methy1, 2- pyrrolidinone \\
\hline 13 to 15 & CT60 & $0^{\circ}$ & Epoxy resin with 20\%(wr) 1-Methy1, 2- pyrrolidinone \\
\hline
\end{tabular}

\begin{tabular}{|c|c|c|l|c|c|}
\hline Fabric & Density & Thickness & Fiber type & Weft tows $/ \mathrm{cm}$ & Warp tows/cm \\
\hline C240 & $240 \mathrm{~g} / \mathrm{m}^{2}$ & $290 \mu \mathrm{m}$ & AKSAKA TM A-38 3K 200tex & $\mathbf{6}$ & $\mathbf{6}$ \\
\hline C/A68 & $68 \mathrm{~g} / \mathrm{m}^{2}$ & $110 \mu \mathrm{m}$ & $\begin{array}{c}\text { TORAYKA T300 } 1 \mathrm{~K} J 67 \mathrm{tex} / \\
\text { KEVLAR } 4922 \text { tex }\end{array}$ & $\mathbf{6 . 5}$ & $\mathbf{6 . 5}$ \\
C160 & $160 \mathrm{~g} / \mathrm{m}^{2}$ & $180 \mu \mathrm{m}$ & AKSAKA TM A-38 3K 200tex & $\mathbf{4}$ & $\mathbf{4}$ \\
\hline F 61 & $61 \mathrm{~g} / \mathrm{m}^{2}$ & $100 \mu \mathrm{m}$ & KEVLARS MAIN \\
\hline CT60 & $60 \mathrm{~g} / \mathrm{m}^{2}$ & $80 \mu \mathrm{m}$ & PYROFIL TM HR $4012 \mathrm{~K}$ & $\mathbf{1 3 . 5}$ & $\mathbf{1 3 . 5}$ \\
\hline
\end{tabular}

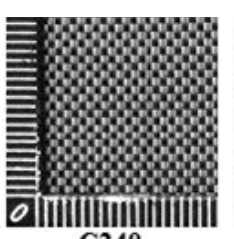

C240

$-1-2-3-4-5-6-7$

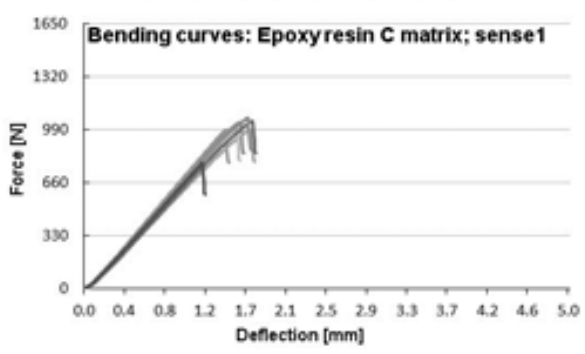

$-1-2-3-4-5-6-7$

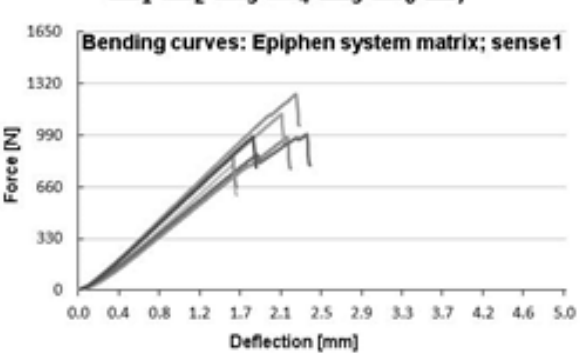

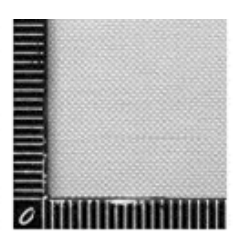

A61

$$
-1-2-3-4-5-6-7
$$

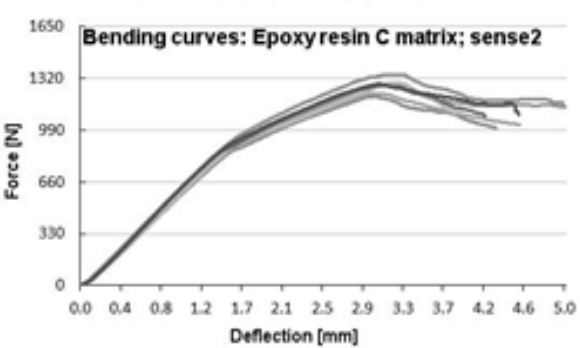

$-1-2-3-4-5-6-7$

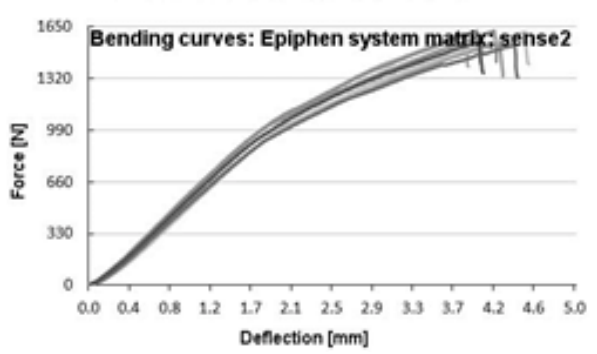

Table 1

THE STRUCTURE OF COMPOSITE PLATES
Fig. 1. Images of the five fabrics used as reinforcement
Fig. 2. Bending curves for Epoxy Resin C matrix composites (seven samples for each loading sense)

Fig. 3. Bending curves for Epiphen system matrix composites (seven samples for each loading sense) 


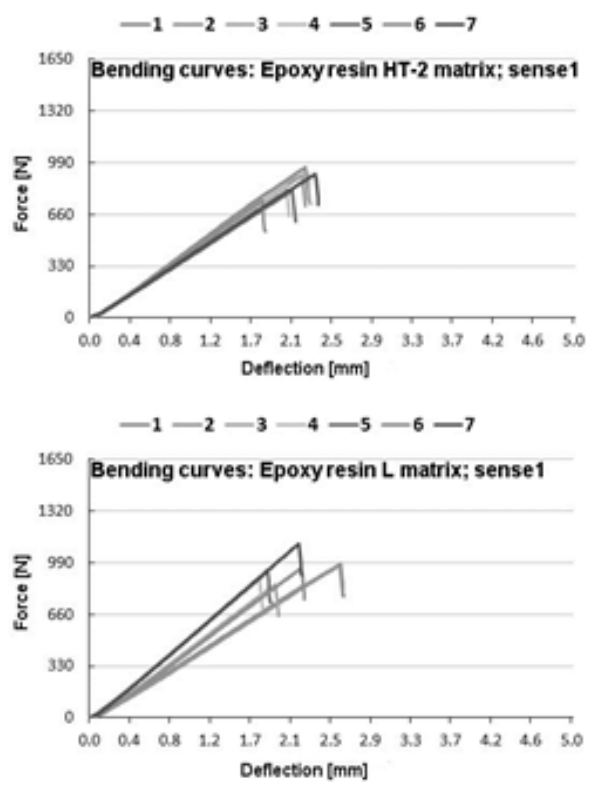

Finally samples for bending and tensile tests were extracted by high pressure water jet cutting machine were extracted. Meantime small parts of plates were prepared for thermal tests (thermal expansion and DSC analysis). The tensile samples were used also (priory the tensile test) to analyse the electromagnetic properties of materials.

\section{Results and discussions}

Firstly, in order to prove the controllable strength, bending tests were performed according to ISO 178/2001 but loading the samples from both faces of material (from the layer with the lower concentration of 1-Methyl, 2- pyrrolidinone to the layer with the higher concentration and vice versa). The tests were performed on an Instron 8802 machine that had been set to stop test if there is value of loading drops more than $70 \%$ from the actual value. The results are presented in figure 2-5 and it is easily observable that the bending curves (force vs. displacement) are different depending on the loading sense. The next notations had been used in the bending graphs: 1 for the case of loading from the layer with 0\% 1-Methyl, 2- pyrrolidinone to the one with 20\% and 2 from the layer with 20\% 1-Methyl, 2pyrrolidinone to the one with $0 \%$.

Because of the machine settings no sample was broken during the tests and the presented curves allow one important conclusion - the hardest layer is failing first no matter the matrix when it is directly exposed to bending
$-1-2-3-4-5-6-7$

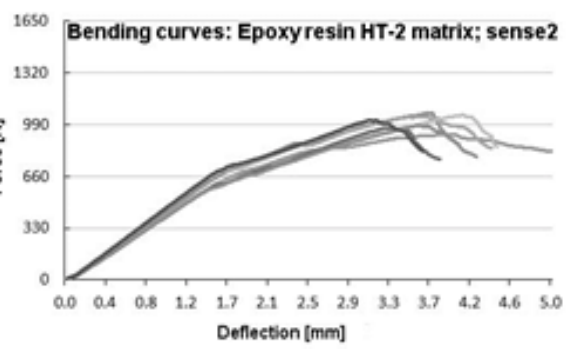

$-1-2-3-4-5-6-7$

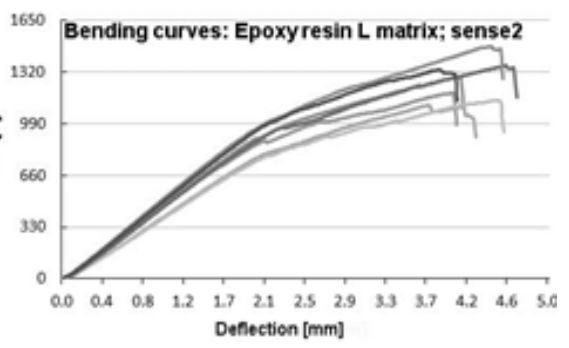

Fig. 5. Bending curves for Epoxy Resin L matrix composites (seven samples for each loading sense)

load. Analysing also the average results presented in figure 6 other conclusions are pointed out: the Epiphen system leads to best bending response while the Epoxy Resin HT2 leads to the lowest response. For each type of matrix it is noticeable the fact that on the 2-sense of bending there are critical points almost on the same displacement as in the case of 1-sense of bending the tests are automatically stopped. In figure 6 there had been used the following notations: C for Epoxy resin C, E for Epiphen epoxy system, $\mathrm{H}$ for Epoxy resin HT-2 and L for Epoxy resin L.

Tensile tests were also performed according DIN EN ISO 527 with rectangular samples $250 \times 10 \times 4 \mathrm{~mm}$ with $25 \mathrm{~mm}$ at each end as gripped zones and engaged length of $200 \mathrm{~mm}$. The machine was also set to stop tests at any variation (drop off) of $70 \%$ from actual value of loading. For the tensile tests there were tested two types of samples: first type denoted as 0 are cut out such as their length is parallel with the warp direction of external layers, the second type denoted as 45 are cut such as their length is inclined at $45^{\circ}$ reported at the warp direction of external layers. The tensile curves (force vs. elongation) are shown in figure 7-10. In these figures are also presented pictures of some tested samples were are observable fractures of external layers (with low concentration of 1-Methyl, 2pyrrolidinone) and massive debonding at the level of A61 layers meaning that the interphase is of poor quality due

$-\mathrm{C} 1-\mathrm{C} 2$
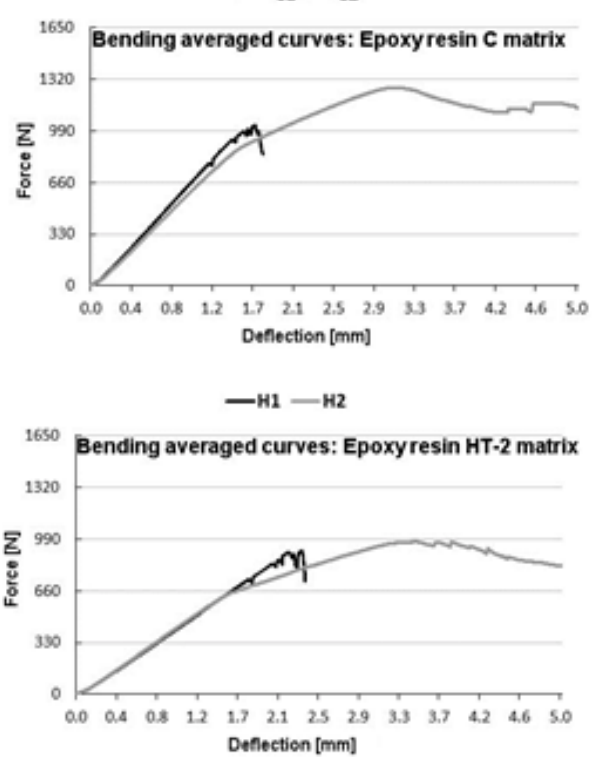
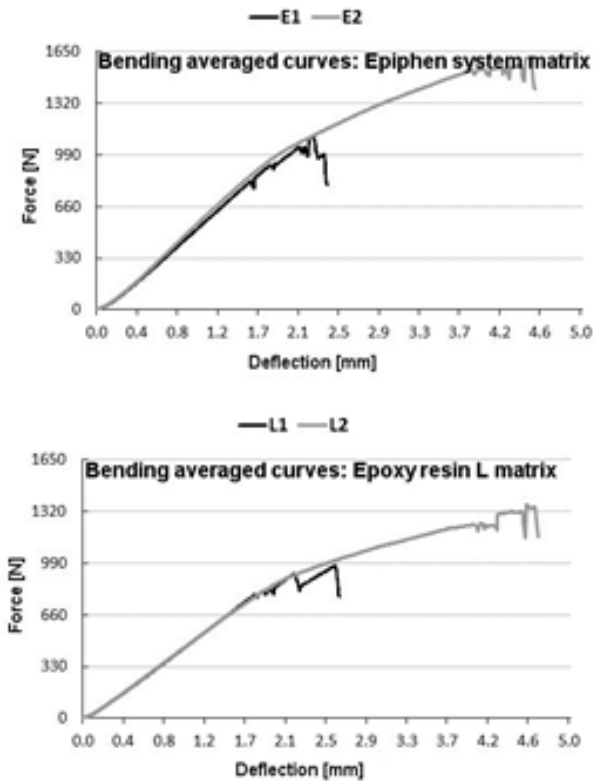

Fig. 6. Bending average curves 
the presence of 1-Methyl, 2- pyrrolidinone. In this respect perhaps the critical points visible on the bending curves (for the 2-sense) might be associated with massive fracture of matrix betw een A61 layers and the adjacent ones. If in the case of bonding the best response was observed for Epiphen epoxy system, in the case of tensile tests the best response is achieved for Epoxy resin L.

In the case of 45-type samples it is noticeable the fact there are not appearing debondings (as in the case of 0 type samples) perhaps because, in this case there are not appearing inter-layer interactions because the loading effort is applied mainly on the layers containing aramid fibres. Another effect (also observable in pictures - in this case the pictures from the right side of figures 7-10) is that all the samples are twisted as a consequence of sharing and torsion. The effect is not observable in the pictures from the left side of figures 7-10.

Figure 11 shows the averaged tensile curved for tested materials both for 0 -type and 45-type samples. For the 0 type samples it can be seen that the materials with matrix of Epoxy resin C, HT-2 and L are failing almost at the same elongation meaning that not the matrix is the one that fails but the reinforcement all the three resins being rigid. In the case of Epiphen epoxy system (with low rigidity) the failing elongation is lower. It had been reported a flow of fabric reinforced thermoset polymers and this flow is corresponding to inclined loading i.e. for samples that are not cut along the warp or the weft of the fabric. In this study the 0-type samples are containing more fibres on the loading direction (carbon fibres mainly) while the 45type samples are containing more fibres oriented at $45^{\circ}$ (again mainly carbon fibres) that is why in the case of 45types samples it might be noticed the flow of material (mostly for Epoxy resin HT-2 and Epiphen RE4020/DE4020).

There is another fact that is possible to have a strong influence in bending and tensile behaviour of studied materials namely the forming technique. The A61 fabric is very thin and since the forming technique impose its impregnation with pre-polymer mixture when it is placed into the mould, in this case above the C160 fabric, it will be affected not only by its own waviness but also by adjacent fabric waviness (it is not the case of contact between A61 layer and CT60 because last one has almost zero waviness). This interpretation might explain also the twisted aspect of 45-type samples after tests.

Regarding the bending modulus and tensile modulus (fig. 12) it is easily observable that in the case of the bending tests the values are closed without respect for loading
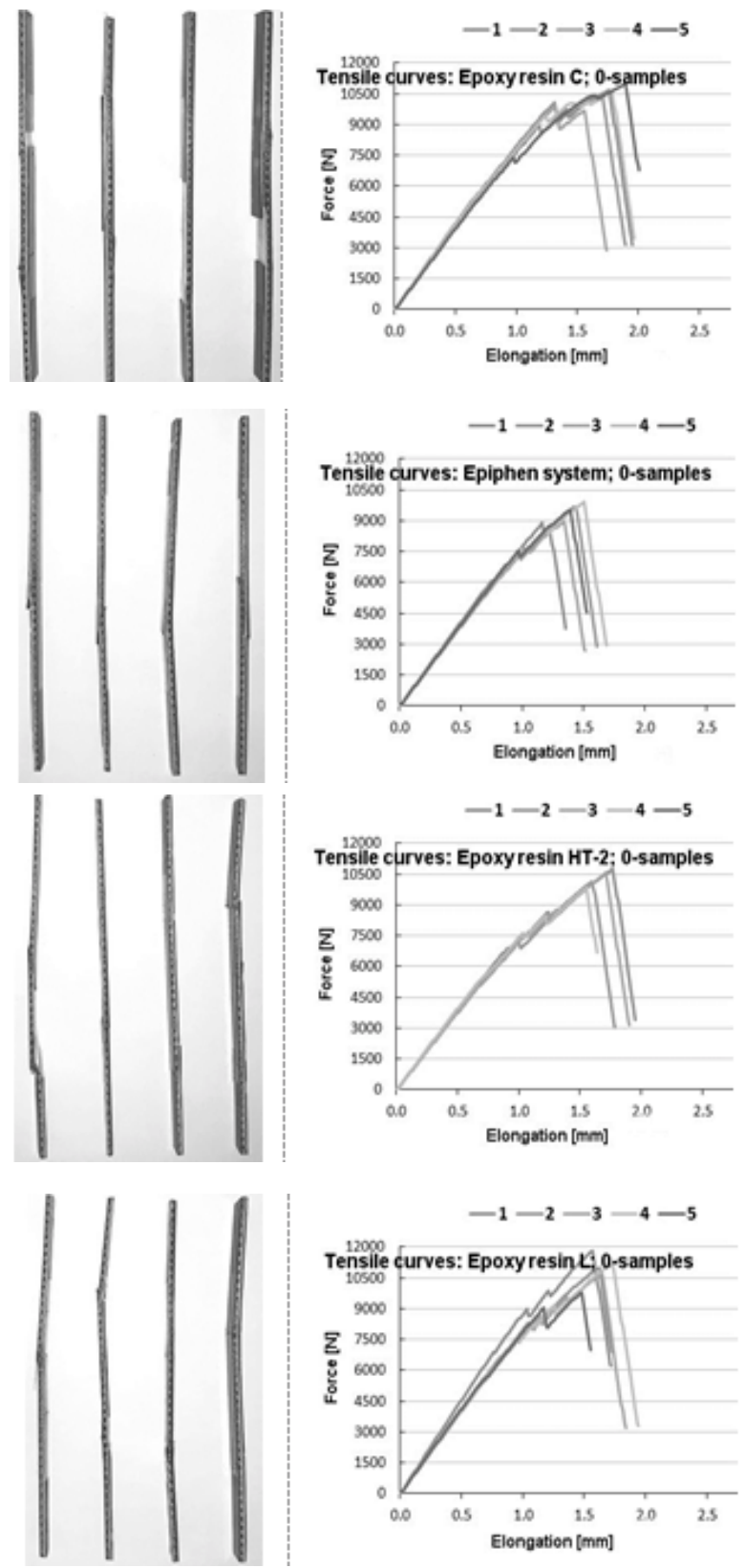
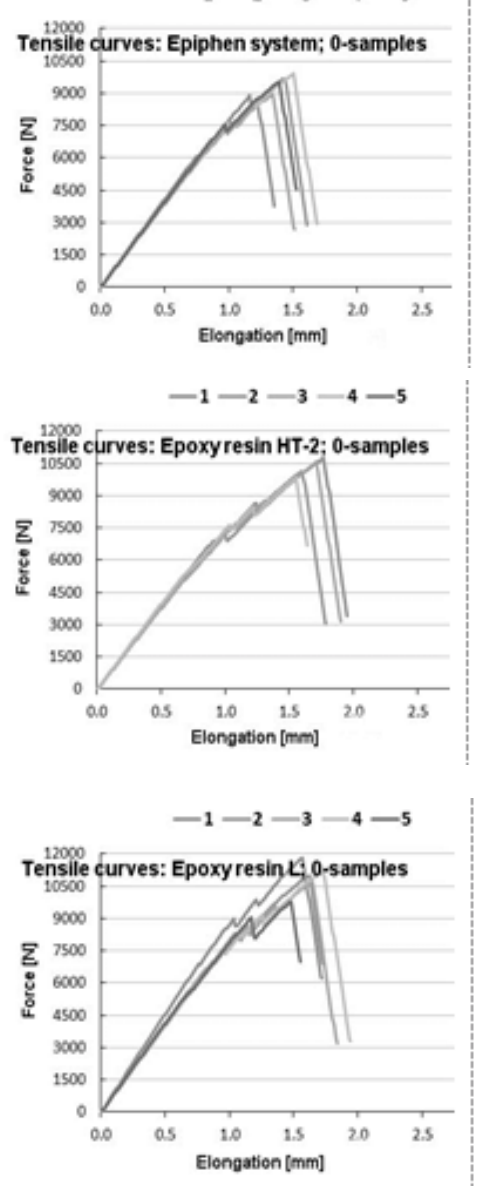
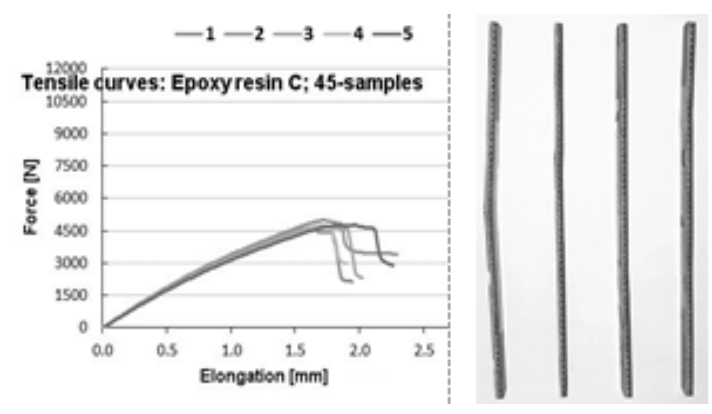

Fig. 7. Tensile curves for Epoxy Resin C matrix materials (left $0^{\circ}$, right $45^{\circ}$ )
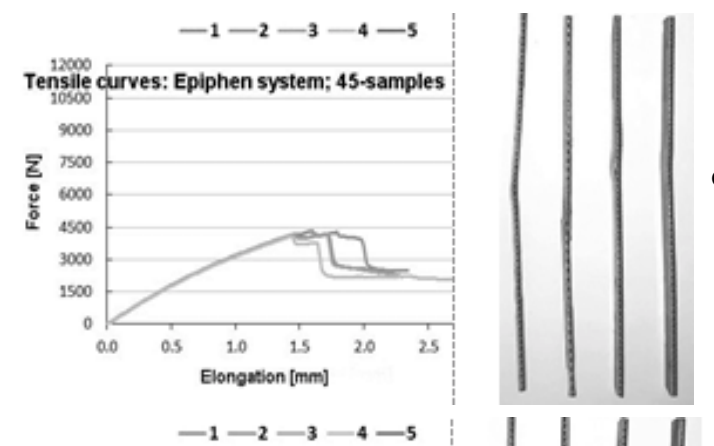

Fig. 8. Tensile curves for Epiphen system matrix materials (left $0^{\circ}$, right $45^{\circ}$ )
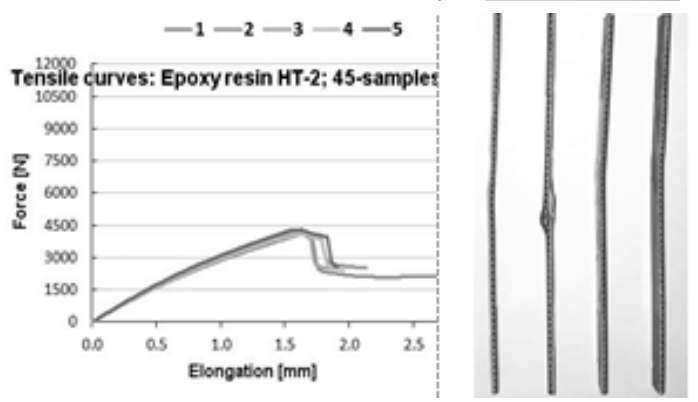

Fig. 9. Tensile curves for Epoxy Resin HT-2 matrix materials (left $0^{\circ}$, right $45^{\circ}$ )

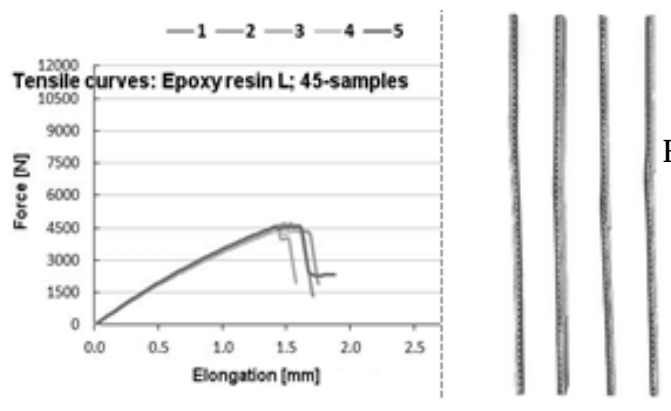

Fig. 10. Tensile curves for Epoxy Resin L matrix materials (left $0^{\circ}$, right $45^{\circ}$ ) 

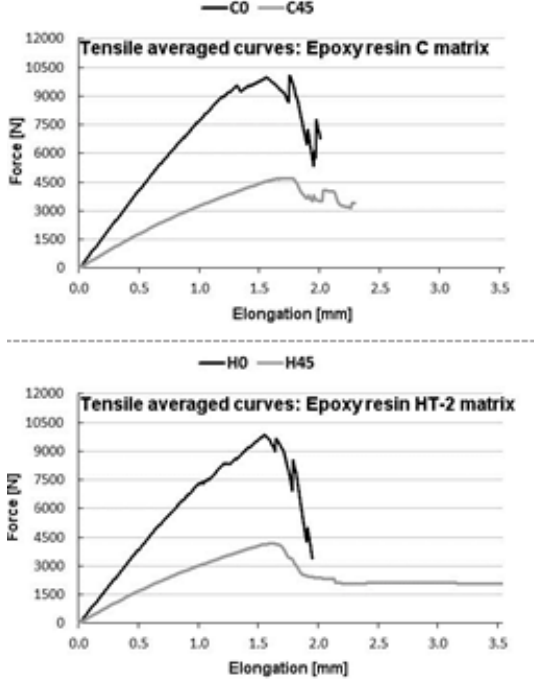

$=1 \pm 2$

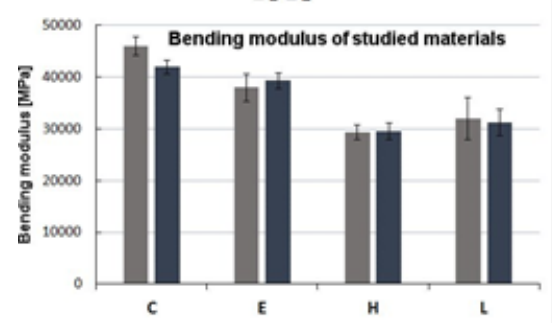

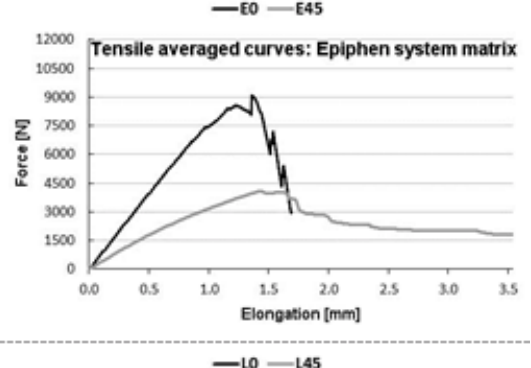

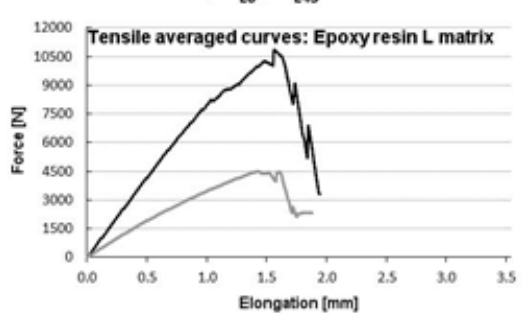

$=\sigma=45^{\circ}$

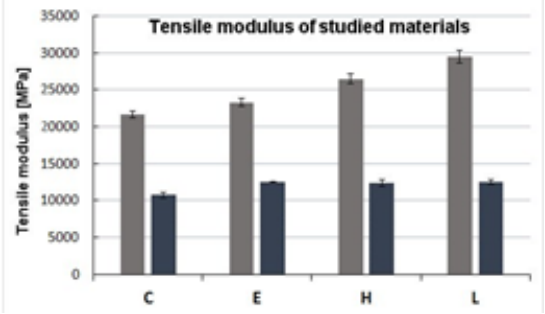

Fig. 11. Averaged tensile curves of studied materials sense (even if there are some differences that can be put on measurement errors) - and this conclusion might be taken just analysing the averaged bending curves in which the first segments of curves are superposed. In the case of tensile modulus in the case of 0 -type samples the parameter depends on matrix (with best response for Epoxy resin $\mathrm{L}$ ) while for the 45-type samples might be said that the tensile modulus is not depending on matrix but on reinforcement.

\section{Conclusions}

The aim of this study was to design and from a composite material with controllable strength and it was achieved since the bending response of formed materials depends on the loading sense. The achievement was possible due to the use of 1-Methyl, 2- pyrrolidinone (a well-known solvent) that allow control over polymer strength. The forming technique - wet lay-up - had permitted obtaining a linear gradient of concentration for 1-Methyl, 2pyrrolidinone and, as a consequence, a graduated strength material (from the matrix point of view).

In the case of bending tests there were not observed debondigs but they appeared during the tensile test (for the samples with high concentration of fibres along the loading direction). It is possible that those debonding appeared even during the bending tests (the critical points on the averaged curves) but their effects are not decidable at a visual inspection.

The forming technique might explain the twisted aspect of tensile tested 45-type samples due to the double waviness of $A 61$ fabric layers (its own one and the one of adjacent layer of $\mathrm{C} 160$ fabric). The flow of 45-types samples (during tensile tests) might be explained by the massive presence of $45^{\circ}$ oriented fibres with respect to the loading direction.

The bending modulus does not depend on the sense of loading (with respect for each matrix) but the bending behaviour of materials strongly depends on the loading sense. The tensile modulus depends on the nature of matrix (for the 0-type samples) but seems to be independent of matrix nature and strongly depends on the reinforcement.

Electromagnetic properties of materials had been investigated and their thermal properties are under investigation together with absorption properties in order to completely characterize the formed materials. Also is necessary to form other materials - with other fabric reinforcement structures such as to avoid debonding and in this case special treatment should be applied to each type of fabric prior to formation.

\section{References}

1. NAEBE, M., SHIRVANIMGHADDAM, K., Functionally graded materials: A review of fabrication and properties, Applied Materials Today, 5 (2016), pp. 223-245, http://dx.doi.org/10.1016/j.apmt.2016.10.001.

2. VOYIADJIS, G. Z., FAGHIHI, D., ZHANG, Y., A theory for grain boundaries with strain-gradient plasticity, International J ournal of Solids and Structures, 51 (2014), pp. 1872-1889, http://dx.doi.org/10.1016/ j.ijsolstr.2014.01.020.

3. POLIZZOTTO, C., Stress gradient versus strain gradient constitutive models within elasticity, International J ournal of Solids and Structures, 51 (2014), pp. 1809-1818, http://dx.doi.org/10.1016/j.jjsolstr.2014.01.021. 4. LIU, T.-J . ZHANG, C., WANG, Y.-S., XING, Y.-M., The axisymmetric stress analysis of double contact problem for functionally graded materials layer with arbitrary graded materials properties, International J ournal of Solids and Structures, 96 (2016), pp. 229-239, http://dx.doi.org/ 10.1016/j.ijsolstr.2016.06.006.

5. LIEW, K.M., ZHAO, X., FERREIRA, A.J.M., A review of meshless methods for laminated and functionally graded plates and shells, Composite Strucutres, 93 (2011), pp. 2031-2041, doi:10.1016/ j.compstruct.2011.02.018.

6. JHA, D.K., KANT, T., SINGH, R.K., A critical review of recent research on functionally graded plates, Composite Strucutres, 96 (2013), pp. 833-849, http://dx.doi.org/10.1016/j.compstruct.2012.09.001.

7. SHEN, H.-S., nonlinear analysis of functionally graded fiber reinforced composite laminated beams in hygrothermal environments, Part I: Theory and solutions, Composite Structures, 125 (2015), pp. 698-705, http://dx.doi.org/10.1016/j.compstruct.2014.12.024. 
8. SHEN, H.-S., nonlinear analysis of functionally graded fiber reinforced composite laminated beams in hygrothermal environments, Part I: Numerical results, Composite Structures, 125 (2015), pp. 706712, http://dx.doi.org/10.1016/j.compstruct.2014.12.023.

9. AMIRPOUR, M., DAS, R., BICKERTON, S., An elasto-plastic damage model for functionally graded plates with in-plane material properties variation: Material model and numerical implementation, Composite Structures, 163 (2017), pp. 331-341, http://dx.doi.org/10.1016/ j.compstruct.2016.12.020.

10. GUPTA, A., TALHA, M., Recent development in modelling and analysis of functionally graded materials and structures, Progress in Aerospace Sciences, 79 (2015), pp. 1-14, http://dx.doi.org/10.1016/ j.paerosci.2015.07.001.

11. KUMAR, S., MURTHY REDDY, K.V.V.S., KUMAR, A., ROHINI DEVI, G., Development and characterization of polymer-ceramic continuous fiber reinforced functionally graded composites for aerospace application, Aerospace Science and Technology, 26 (2013), pp. 185191, http://dx.doi.org/10.1016/j.ast.2012.04.002.

12. DUNCAN, O., ALLEN, T., FOSTER, L., SENIOR, T., ALDERSON, A., Fabrication, characterization and modelling of uniform and gradient auxetic foam sheets, Acta Materialia, 126 (2017), pp. 426-437, http:// dx.doi.org/10.1016/j.actamat.2017.01.004.

13. AMIRPOUR, M., DAS, R., SAAVEDRA FLORES, E.I., Analytical solutions for elastic deformation of functionally graded thick plates with in-plane stiffness variation using higher order shear deformation theory, Composites Part B, 94 (2016), pp. 109-121, http:/dx.doi.org/ 10.1016/j.compositesb.2016.03.040.

14. SHEN, H.-S., YANG, D.-Q., Nonlinear vibration of functionally graded fiber reinforced composite laminated beams with piezoelectric fiber reinforced composite actuators in thermal environments, Engineering Structures, 90 (2015), pp. 183-192, http://dx.doi.org/10.1016/ j.engstruct.2015.02.005.

15. CHUNG, D.D.L., Processing-structure-property relationships of continuous carbon fiber polymer-matrix composites, Materials Science and Engineering R, 113 (2017), pp. 1-19, http://dx.doi.org/ 10.1016.j.mser.2017.01.002.

16. ZANTOUT, A.E., ZHUPANSKA, OLESYA I., On the electrical resistance of carbon fiber polymer matrix composites, Composites: Part A, 41 (2010), pp. 1719-1727, doi:10.1016/j.compositesa.2010.08.010.

17. WANG, S., CHUNG, D.D.L., Self-sensing of flexural strain and damage in carbon fiber polymer-matrix composite by electrical resistance measurement, Carbon, 44 (2006), pp. 2739-2751, doi:10.1016/ j.carbon.2006.03.034.

18. ZHU, S., CHUNG, D.D.L., Analytical model of piezorestivity for strain sensing in carbon fiber polymer-matrix structural composite under flexure, Carbon, 45 (2007), pp. 1606-1613, doi:10.1016/ j.carbon.2007.04.012.

19. WANG, D., CHUNG, D.D.L., Through-thickness piezoresistivity in a carbon fiber polymer-matrix structural composite for electricalresistance-based through-thickness strain sensing, Carbon, 60 (2013), pp. 129-138, http://dx.doi.org/10.1016/j.carbon.2013.04.005.

20. YU, G.-C., WU, L.-Z., FENG, L.-J., YANG, W., Thermal and mechanical properties of carbon fiber polymer-matrix composites with a $3 \mathrm{D}$ thermal conductive pathway, Composite structures, 149 (2016), pp. 213-219, http:dx.doi.org/10.2016/j.compstruct.2016.04.010.

21. SHEN, L., LI, J., LIAW, B.M., DELALE, F., CHUNG, J.H., Modeling and analysis of the electrical resistance measurement of carbon fiber polymer-matrix composites, Composites Science and Technology, 67 (2007), pp. 2513-2520, doi:10.1016/j.compscitech.2006.12.020.

21. SEVKAT, E., LI, J., LIAW, B., DELALE, F., A statistical model of electrical resistance of carbon reinforced composites under tensile loading, Composites Science and Technology, 68 (2008), pp. 22142219, doi:10.1016/j.compscitech.2008.04.011.

22. WEN, J., XIA, Z., CHOY, F., Damage detection of carbon fiber reinforced polymer composites via electrical resistance measurement, Composites: Part B, 42 (2011), pp. 77-86, doi:10.1016/j.compositesb. 2010.08.005.

23. NING, Z., LIU, R., ELHAJJAR, R.F., WANG, F., Micro-modeling of thermal properties in carbon fibers reinforced polymer composites with fiber breaks or delamination, Composites Part B, 114 (2017), pp. 247-255, http://dx.doi.org/10.1016/j.compositesb.2017.01.036.

24. STEFANESCU, V., BUNEA, M., CIRCIUMARU, A., Impact analysis of fabric reinforced plates, Mat. Plast., 52, no. 2, 2015, p.198, http:// w w w .revmaterialeplastice.ro/pdf/STEFANESCU \%20V.pd f\%202\%2015.pdf

25.BUNEA, M., BOSOANCA, I., BOSOANCA, R., BODOR, M., CIRCIUMARU, A., Bending and compressive properties of fabric reinforced composites, Mat. Plast., 52, no. 3, 2015, p. 368, http:// www.revmaterialeplastice.ro/pdf/BUNEA\%20M.pdf\%203\%2015.pdf

26. CIRCIUMARU, A., BRIA, V., BIRSAN, I.-G., ANDREI, G., DIMA, D., Some properties of stratified composites, ASME 2010 10th Biennial Conference on Engineering Systems Design and Analysis, ESDA 2010, pp. 679-682, http://proceedings.asmedigitalcollection.asme.org/ proceeding. aspx?articleid $=1618036$

27.BIRSAN, I.G.,CIRCIUMARU, A., BRIA, V., ROMAN, I., UNGUREANU, V., Mechanical characterization of fiber fabrics, Source of the DocumentASME 2010 10th Biennial Conference on Engineering Systems Design and Analysis, ESDA 2010, pp. 671-674, http:// proceedings.asmedigitalcollection.asme.org/proceeding.aspx? articleid $=1618034$

28. MUNTENITA, C., BRIA, V., ENI, C., CIRCIUMARU, A., GRAUR, I., Physical characterization of nano-ferrites modified epoxy resins, Mat. Plast., 53, no. 3, 2016, p. 509, http://www.revmaterialeplastice.ro/pdf/ MUNTENITA\%20C\%203\%2016.pdf

29. GRAUR, IULIA, BOSOANCA, I., BOSOANCA, R., BODOR, M., CIRCIUMARU, A., Thermal analysis of ionic substances doped epoxy, Rev. Chim. (Bucharest), 66, no. 11, 2015, p. 1759 http:// www.revistadechimie.ro/pdf/GRAUR\%201.pdf\%2011\%2015.pdf

30. CIOBOTARIU, O.R., BRIA, V.., GRAUR, I., VOINESCU, D.C., Electric conductivity of modified epoxies, Rev. Chim. (Bucharest), 66, no. 11, 2015, p. 1903

31. GRAUR, I., BOSOANCA, I., BOSOANCA, R., BODOR, M., CIRCIUMARU, A., Thermal analysis of ionic substances doped epoxy, Rev. Chim. (Bucharest), 66, no. 11, 2015, p. 1759

32. BRIA, V., CIRCIUMARU, A., BIRSAN, I.-G., Some properties of starch/ epoxy composites, Mat. Plast., 48, no. 2, 2011, p. 189

Manuscript received: 15.12.2106 